\title{
Assessment of Risk Factors for Type II Diabetes Mellitus on Patients Attending at Three Hospitals in Wolaita Zone, South Ethiopia
}

\author{
Tamene Naba (M.Sc)* \\ Wolaita Sodo University, College of Health Sciences School of Medicine, Physiology Unit, Sodo Ethiopia \\ P.O.B. Wolaita Sodo University 338
}

\begin{abstract}
Diabetes mellitus is one of the most common chronic metabolic disorders of carbohydrates, proteins and fat in almost all countries, and it continues to be increased in magnitude and clinical significance, as lifestyle changes lead to reduce physical activity and increased obesity. A cross sectional study was conducted from July1 to August 15, 2011 in three Hospitals of Wolaita Zone using purposive sampling technique until required sample size of 348 was achieved. Patients with type II diabetes mellitus were selected based on sample size determination technique for single population. Data were collected using semi-structured questionnaire. The data was analyzed by using SPSS version 16.0. Frequencies and graphs were used to describe selected variables.348 study subjects have participated in the study. As per the age distributions $188(54 \%)$ of study participants were found to be above age of 50 years. The mean \pm SD age of type II patients was $51.9 \pm 13.6$ and age range between 19 years and 83 years. Hundred and seventy nine $(51.4 \%)$ of the study participants were males. With respect to educational levels 86 $(24.7 \%)$ of the study participants have completed primary school (grade 1-4) followed by illiterates $75(21.6 \%)$. Regarding income, 106 (30.5\%) of type II diabetic patients have monthly income more than 1500 ETB. A high proportion of risk factors observed in type II diabetes mellitus were being male, older age group greater than 50 , overweight and with higher monthly income. The risk rate of type II diabetes mellitus was higher among urban residence, primary level of education. Most of the diabetic cases had BMI $>25 \mathrm{~kg} / \mathrm{m}^{2}$ which is a risk factor for the development of type II Diabetes.
\end{abstract}

Keywords: Diabetes Mellitus, Hyperglycemia and Risk Factors

DOI: $10.7176 / \mathrm{JBAH} / 10-23-04$

Publication date: December $31^{\text {st }} 2020$

\section{Introduction}

Diabetes mellitus (DM) is a syndrome characterized by a state of chronic hyperglycemia cause disturbance of carbohydrate, fat and protein metabolism, associated with absolute or relative deficiency in insulin secretion or insulin action (1). As per the World Health Organization, diabetes mellitus (DM) is a heterogeneous metabolic disorders characterized by common feature of chronic hyperglycemia with disturbance of carbohydrate, fat and protein metabolism (2).

Diabetes, more properly called diabetes mellitus, is actually a group of diseases involving the inability to produce or use insulin, and resulting in elevated plasma glucose (blood sugar) level and classified as three categories. First, type I diabetes mellitus, Juvenile or insulin-dependent diabetes, involves the inability to produce from the outset. It generally has an early age of onset, is probably irreversible, and accounts for 5-10 percent of all cases. Second, type II, adult-onset or non-insulin dependent diabetes, is 90-95 percent of all cases. Third, gestational diabetes occurs in 2-5 percent of all pregnancies in the U.S. This form of diabetes is not necessarily permanent, but it can predispose both mothers and child to type II diabetes (3-6).

Type II diabetes is associated with older age, obesity, family history of diabetes, history of gestational diabetes, impaired glucose metabolism, lack of physical activity, and race/ethnicity (7). Type II, previously defined as noninsulin-dependent diabetes mellitus (NIDDM) (7). Diabetes can be diagnosed by three methods: first, fasting plasma glucose test with a value of $126 \mathrm{mg} / \mathrm{dL}$ or greater. Second, a non fasting plasma glucose value of 200 $\mathrm{mg} / \mathrm{dL}$ or greater in people with symptoms of diabetes and third an abnormal oral glucose tolerance test with a 2hour glucose value of $200 \mathrm{mg} / \mathrm{dL}$ or greater. Each test must be confirmed, on another day, by any one of the above methods. The criteria used to diagnose diabetes were revised in 1997 (8).

Diabetes is a serious disease that can have a significant impact on health, quality of life, and life expectancy of individuals, as well as on the health-care system. Compared with people without diabetes, diabetic patients have a higher hospitalization rate, longer hospital stays, and increased ambulatory care visits (9).

Research conducted in southern parts of Ethiopia 2010 showed that out of 395 subjects 199 (50.4\%) were diabetics and $196(49.6 \%)$ were non diabetics with nearly equal representation. Among the diabetics $152(76.4 \%)$ had type I diabetes mellitus and 47 (23.4\%) had type II diabetes mellitus (10).

When diabetes is not well managed, it is results with serious complications including heart disease, stroke, blindness, kidney disease, nerve damage and amputations leading to disability and premature mortality. There is 
also a substantial financial cost to diabetes care as well as costs to the lives of people with diabetes (11).

\section{Methods And Materials}

\subsection{Study Area and Period}

Facility based cross sectional study was conducted from July 1 to August 15, 2011, at three Hospitals in Wolaita Zone.

\subsection{Sample Size Determination and Sampling}

Source Population: Diabetic patients registered at three Hospitals in Wolaita Zone.

Study Population: All type II diabetic patients who were on follow-up at the diabetic clinics of three Hospitals in Wolaita Zone registered until August 15, 2011.

\section{Inclusion and Exclusion Criteria}

Inclusion Criteria:

\section{Exclusion Criteria: \\ $>$ Those patients who were unwilling for the interview. \\ $>$ Patients with type I diabetes.}

$>$ Those who were willing to participate in interview.

\subsubsection{Sample size determination.}

A $29 \%$ expected prevalence of type II diabetes in the diabetic clinics of Addis Ababa was considered based on data from studies on relatively similar populations in Addis Ababa (12). No current data are available on the prevalence of diabetes at three Hospitals in Wolaita Zone. The actual sample size was calculated using the following single population proportion formula.

$\mathrm{n}=\left(\mathrm{Z}_{\alpha / 2}\right)^{2} \mathrm{X} \mathrm{P}(1-\mathrm{P}) \div \mathrm{d}^{2}$

Where

$\mathrm{n}=$ required sample size

$\mathrm{z}=1.96(95 \%$ confidence level for two side)

$\mathrm{p}=29 \%$ ( proportion of type 2 diabetes mellitus)

$\mathrm{d}=$ margin of error $(5 \%)$

Therefore the value of $\mathrm{n}$ was calculated as follows

$\mathrm{n}=(1.96)^{2} \mathrm{x} 0.29(1-0.29) \div 0.05^{2}$

$=316.4 \approx 316$

Non-responsive rate $10 \%$ of contingency was used. $\mathrm{n}=348$

\subsubsection{Sampling Technique}

The study was conducted using purposive sampling techniques until the required sample size was attained. Those study participants who refused to participate in the study were considered non-respondents and the next. Three trained data collector (nurses) and two supervisors were assigned in each health facility. After identifying the study participants, the data collectors were informed the aim of the study, confidentiality issue and informed consent to all of the study participants; interviewer-administered data collection method was employed in selected type II diabetic patients. The principal investigator and the supervisor were supervising collected data and checked their completeness.

\section{Data collection instrument and processing}

Questionnaire

A standardized interview based on structured questionnaire was carried out by five public health workers who were well trained interview techniques and all questionnaire details, Information was obtained from the interview including history of family, sex, age groups, body built, food habits, income, educational level, physical activity levels, blood pressure and residence.

II. Weight Scale

$>$ The weight of patients was measured.

$>$ The height of patient of patients was measured.

BMI was calculated and classified as follow (13).

$>$ Underweight $<18.5 \mathrm{~kg} \mathrm{~m}-1$

$>$ Normal $18.5-24.9 \mathrm{~kg} \mathrm{~m}-1$

$>$ Overweight $25.0-29.9 \mathrm{~kg} \mathrm{~m}-1$

III. Sphygmomanometers

$$
\text { Obese } \geq 30.0 \mathrm{~kg} \mathrm{~m}-1
$$

$>$ Patients were announced to avoid having meals at least thirty minute before BP measurements.

$>$ A cuff which is attached to a manometer (sphygmomanometer) was wrapped around the upper arm 
and was inflated until the brachial artery is completely occluded.

$>$ The diaphragm of stethoscope is placed over the brachial artery distal to the cuff. First the systolic pressure was estimated by palpitation method end the cuff was then allowed to deflate slowly.

$>$ When the cuff reaches systolic pressure, a clear tapping sound was heard in time with the heart beat. As the cuff deflates further, the sounds became quieter, but became louder again before disappearing altogether. The point at which the sounds disappear is the diastolic pressure

$>$ Blood pressure was measured 3 times

$>$ Blood pressure was measured on the right arm, with the subject seated after 10 minutes rest, using a standard clinical mercury sphygmomanometer with an appropriate cuff size. Hypertension was diagnosed according to WHO criteria [100] if systolic pressure was $\geq 140 \mathrm{mmHg}$ or diastolic pressure $\geq 90 \mathrm{mmHg}$.

\subsection{Data Analysis}

The collected data were subjected for statistical analysis. The collected data were coded, checked for completeness and missing value, entered and analyzed by using SPSS version 16.0. Frequencies and graphs were used to describe selected variables.

\subsection{Operational Definitions of Terms}

Risk Factor: Any attribute, characteristic or exposure of an individual, which increases the likelihood of developing the disease of interest.

Fasting Blood Glucose: Blood glucose estimation obtained from a subject who has undergone an overnight fast from any food or drink (excluding water or clear, plain tea) for at least 8 hours.

Obesity: A body mass index (BMI) $\geq 30.0 \mathrm{~kg} \mathrm{~m}-1$.

Overweight: $A B M I \geq 25.0$ but less than $30.0 \mathrm{~kg} \mathrm{~m}-1$.

Normal Fasting Glucose: A capillary whole blood fasting glucose level $<5.6 \mathrm{mmol} 1-1$ (100mg dl-1).

Hypertension: The average of casual systolic blood pressure readings $\geq 140 \mathrm{mmHg}$ and/or diastolic pressure readings $\geq 90 \mathrm{mmHg}$.

Sedentary Lifestyle (Physical inactivity): In this study is measured as a response of being always or usually engaged in light/leisure activities for most days of the week or a response of sometimes/never engagement in moderate to intense physical activity.

Vigorous (physical activity) -Outside work for most days of the week that would add up to at least three hours (14).

Positive Family History of Diabetes: Is a reported history of diabetes in the father, mother, full brother or sister, or the respondent.

Heavy Alcohol Consumption: Refers to the average consumption of more than 3 standard alcoholic drinks per day for men $(\approx 30 \mathrm{gm}$ of alcohol) or $>2$ alcoholic drinks (or20 gm alcohol) for women. A standard alcoholic drink is the equivalent of one glass $/ \mathrm{can} /$ bottle $(330 \mathrm{ml})$ of regular beer (with $3 \%$ ethanol), one glass $(100 \mathrm{ml})$ of wine $(10 \%$ ethanol) or one glass or measure $(40 \mathrm{ml})$ of distilled spirit, each of which adds up to about $10 \mathrm{~g}$ of ethanol per drink (14).

Cigarette Smoking: Refers those have smokes 1-14, 15-24, and $\geq 25$ cigarettes/d, medium, high, very high smokers respectively.

\section{Results}

\section{Socio-demographic Characteristics}

A total of 348 study participants were interviewed during the study period. The response rate was $90 \%$. Among 348 patients involved in the study majority 179 (51.4\%) were males. As per the age distributions $188(54 \%)$ of study participants were in age group greater than 50 years. The mean \pm SD age of type II patients was $51.9 \pm 13.6$ and range between 19 years and 83 years. Regarding marital status of the respondents, $303(87.1 \%)$ of them were married. Among the respondents, 209 (60.1\%) of them were Wolaita by ethnicity; followed by Gurage $50(14.4 \%)$. Protestant was the predominant religion which accounted for $170(48.9 \%)$ followed by Orthodox $110(31.6 \%)$. With respect to educational status, $86(24.7 \%)$ have completed primary school (grade 1-4) followed by illiterates $86(24.7 \%)$ 
Table 1A: Socio-Demography Characteristics of Type II Diabetic Patients at Three Hospitals in Wolaita Zone, South Ethiopia, 2011

\begin{tabular}{|c|c|c|}
\hline $\begin{array}{l}\text { Socio-Demographic } \\
\text { Characteristics (Respondents) }\end{array}$ & Frequency & Percent $(\%)$ \\
\hline \multicolumn{3}{|l|}{ Sex } \\
\hline Male & 179 & 51.4 \\
\hline Female & 169 & 48.6 \\
\hline \multicolumn{3}{|l|}{ Age } \\
\hline Mean, SD & & $51.9 \pm 13.6$ \\
\hline $18-30$ & 22 & 6.3 \\
\hline $31-40$ & 50 & 14.4 \\
\hline $41-50$ & 88 & 25.3 \\
\hline$>50$ & 188 & 54.0 \\
\hline \multicolumn{3}{|l|}{ Religion } \\
\hline Orthodox & 110 & 31.6 \\
\hline Protestant & 170 & 48.9 \\
\hline Catholic & 12 & 3.4 \\
\hline Muslim & 56 & 16.1 \\
\hline \multicolumn{3}{|l|}{ Ethnicity } \\
\hline Wolaita & 209 & 60.1 \\
\hline Oromo & 20 & 5.7 \\
\hline Gurage & 50 & 14.4 \\
\hline Amara & 32 & 9.2 \\
\hline Hadia & 15 & 4.3 \\
\hline Others* & 22 & 6.3 \\
\hline \multicolumn{3}{|l|}{ Marital status } \\
\hline Single & 20 & 5.7 \\
\hline Married & 303 & 87.1 \\
\hline Divorced & 5 & 1.5 \\
\hline Widowed & 20 & 5.7 \\
\hline \multicolumn{3}{|l|}{ Educational status } \\
\hline MSc. and above & 5 & 1.4 \\
\hline First Degree & 35 & 10.1 \\
\hline Diploma & 19 & 5.4 \\
\hline High school (9-12) & 61 & 17.5 \\
\hline Primary School (5-8) & 67 & 19.3 \\
\hline Primary School (1-4) & 86 & 24.7 \\
\hline Illiterate & 75 & 21.6 \\
\hline
\end{tabular}

*Others $=$ Silte, Kanbata, Gamo,Dawuro, Tigre

As per the income, 106 (30.5\%) of type II diabetic patients have earned monthly income more than 1500 ETB. More than half of type II patients, 277 (79.6\%) were urban residents. The majorities 301 (86.5\%) of patients were no family history of diabetes mellitus. As far as occupational status is concerned, $119(34.2 \%)$ of the respondents were house wives, followed by Government employee 109 (34.2\%). As shown in table 1B, majority 169 (48.6\%) of study participants were found to be normotensive. 
Table 1B: Socio-Demography Characteristics of Type II Diabetic Patients at Three Hospitals in Wolaita Zone, South Ethiopia, 2011

\begin{tabular}{|c|c|c|}
\hline $\begin{array}{l}\text { Socio-Demographic } \\
\text { Characteristics (Respondents) }\end{array}$ & Frequency & Percent $(\%)$ \\
\hline \multicolumn{3}{|l|}{ Income per month } \\
\hline$<200$ Birr & 25 & 7.2 \\
\hline $200-499$ & 57 & 16.4 \\
\hline 500-999 Birr & 70 & 20 \\
\hline 1000-1499 Birr & 90 & 25.9 \\
\hline$\geq 1500$ & 106 & 30.5 \\
\hline \multicolumn{3}{|l|}{ Residence } \\
\hline Urban & 277 & 79.6 \\
\hline Rural & 71 & 20.4 \\
\hline \multicolumn{3}{|l|}{ Family's history } \\
\hline Yes & 47 & 13.5 \\
\hline $\mathrm{No}$ & 301 & 86.5 \\
\hline \multicolumn{3}{|l|}{ Occupation } \\
\hline Merchant & 65 & 18.7 \\
\hline House wife & 119 & 34.2 \\
\hline Gov. Employee & 109 & 31.3 \\
\hline Farmers & 28 & 8.0 \\
\hline Others** & 27 & 7.8 \\
\hline \multicolumn{3}{|l|}{ Blood Pressure } \\
\hline Hypotensive & 34 & 9.7 \\
\hline Normotensive & 169 & 48.6 \\
\hline Hypertensive & 145 & 41.7 \\
\hline
\end{tabular}

Others** Waiter, Carpenter, Construction Worker, Daily labors and guard

Frequency Distribution of Life Style Factors Affecting the Incidence of Type II Diabetic Patients

Table 2 showed that the value of BMI and the level of physical activities of the study participants. Among the total study participants, 17 (4.9\%) were underweight, 135 (38.8\%) were having average BMI. About $196(56.3 \%)$ of type II patients were overweight and obese.

Regarding physical activities, 291 (83.7\%) of the patients were having sedentary life followed by vigorous physical activities 57 (16.3\%).

Table 2: Frequency Distribution of Life Style Factors Affecting the Incidence of Type II Diabetic Patients at Three Hospitals in Wolaita Zone, South Ethiopia, 2011

\begin{tabular}{|l|c|c|}
\hline Lifestyle Characteristics & Frequency & Percent \\
\hline BMI & & \\
\hline$<18.5$ & 17 & 4.9 \\
\hline $18.5-24.9$ & 135 & 38.8 \\
\hline $25-29.9$ & 118 & 33.9 \\
\hline$>30$ & 78 & 22.4 \\
\hline Exercise & & \\
\hline Sedentary Life & 291 & 83.7 \\
\hline Physical Activities & 57 & 16.3 \\
\hline
\end{tabular}

\section{Frequency Distribution of the Effects of Dietary Habit on Type II Diabetic Patients}

As per the dietary habit, $45(12.9 \%)$ of the study participants were usually eat vegetable followed by eating fruit $21(6.1 \%)$. Most $282(81 \%)$ of study participants were usually eat sugar and oil excess. Frequency of eating fruits among type II diabetic patients found that, 229 (65.8\%) were eat fruits occasional followed by eating fruits once a day $61(17.5 \%)$. (Table 3) 
Table 3: The Effects of Dietary Habit on Type II Diabetic Patients at Three Hospitals in Wolaita Zone, South Ethiopia, 2011

\begin{tabular}{|l|l|l|}
\hline Dietary Habit & Frequency & Percent \\
\hline Diet & & \\
\hline Vegetables & 45 & 12.9 \\
\hline Fruit & 21 & 6.1 \\
\hline Sugar and Oil Excess & 282 & 81 \\
\hline Frequency of Eating fruit & & \\
\hline Never & 34 & 9.8 \\
\hline Occasional & 229 & 65.8 \\
\hline Once a day & 61 & 17.5 \\
\hline 2-4 times per day & 24 & 6.9 \\
\hline
\end{tabular}

\section{Frequency Distribution of effect of Substance Use on Type II Diabetic Patients}

Among 348 participants 311 (89.4\%) were non smokers. Only few participants $37(10.6 \%)$ were cigarette smokers. Of these about 40 (11.5\%) were daily smokers followed occasional smokers 34 (9.8\%). Regarding khat chewing, $74(21.3 \%)$ of type II patients were found to be khat chewers. Most 40 (11.5\%) were chew daily. About $31(8.9 \%)$ of type II patients were chew two times per a week followed by those who chew three times per month $3(0.9 \%)$. About $32(9.2 \%)$ of were started chewing khat more than two years. About $170(48.9 \%)$ of study participants were alcohol drinker. Of these most $86(24.7 \%)$ were drinks daily followed by drinking two times per a week $72(20.8 \%)$. Majority $94(27.0 \%)$ of study participants were drink more than three standard drink. (Table 4)

Table 4: Frequency Distribution of effect of Substance Use on Type II Diabetic Patients at Three Hospitals in Wolaita Zone, South Ethiopia, 2011

\begin{tabular}{|c|c|c|}
\hline Substance Use & Frequency & Percent \\
\hline \multicolumn{3}{|l|}{ Smoking Cigarettes } \\
\hline Yes & 37 & 10.6 \\
\hline No & 311 & 89.4 \\
\hline \multicolumn{3}{|l|}{ The Number of Cigarettes Per Day } \\
\hline $1-14$ & 15 & 40.5 \\
\hline $15-25$ & 10 & 27.1 \\
\hline$>25$ & 12 & 32.4 \\
\hline \multicolumn{3}{|l|}{ Chew Khat } \\
\hline Yes & 74 & 21.3 \\
\hline No, I have Never & 274 & 78.7 \\
\hline \multicolumn{3}{|l|}{ Frequency of Chewing Khat } \\
\hline Daily & 40 & 11.5 \\
\hline Occupational & 34 & 9.8 \\
\hline \multicolumn{3}{|l|}{ Duration of Starting chewing Khat } \\
\hline One Month & 5 & 1.4 \\
\hline One Year & 13 & 3.7 \\
\hline Two Year & 24 & 6.9 \\
\hline More Than Two Years & 32 & 9.2 \\
\hline \multicolumn{3}{|l|}{ Drink Alcohol } \\
\hline Yes & 170 & 48.9 \\
\hline No & 178 & 51.1 \\
\hline \multicolumn{3}{|l|}{ Frequency of Drinking Alcohol } \\
\hline \multicolumn{3}{|l|}{ Daily } \\
\hline Two Times Per week & 86 & 24.7 \\
\hline Three Times Per month & 72 & 20.8 \\
\hline \multicolumn{3}{|l|}{ No. Alcohol Drinking per Day } \\
\hline One Standard* & 4 & 1.1 \\
\hline Two Standard Drink** & 18 & 5.2 \\
\hline Three Standard Drink** & 54 & 15.5 \\
\hline More than three standard drink & 94 & 27.0 \\
\hline
\end{tabular}

*Mild Alcohol Consumption =One standard drink per day

**Moderate Alcohol Consumption= Two standard drink per day+ Three standard drink per day

*** Heavy Alcohol Consumption= More than three standard drink per day 


\section{Discussions}

The distribution of type II diabetes mellitus among male and female patients was found to be different. According to the finding of the present study, type II DM is more prevalent among males than in females. This finding is in agreement with the study conducted in India by Muhammad $\mathrm{K}$ et al., 2010, which showed that higher prevalence $(53.3 \%)$ rate among male than relatively lower prevalence $46.6 \%$ among females (15). The above study supports our finding. The possible explanation for this could be due to the fact that males are more exposed to risk factors to DM.

Some other studies are contradicted to the present finding, which showed that higher prevalence in female than males (16). In addition to the above results, there are also other studies which showed that similar prevalence between males and females (17-19). The women enrolled in this study were mainly housewives whereas men were working outside the home and household income is mostly controlled by men. These factors may have influenced the difference in the diabetes prevalence.

In this study $188(54.0 \%)$ of the study participants belonged to the age group of $>50$ years. This result is in agreement with the study conducted in India by Muhammad $\mathrm{K}$ which showed that majority of the study participants belong to the age group of 60 and above (15). However, this is contradicted with the study conducted by Shobha M et al, where they found that majority of patients belonged to age group 46 to 50 years of age (20). But they specified that there is increased onset of diabetes among younger age group in Indians.

As per distribution of education, 86 (24.7\%) were primary level of education (grade 1-4). About $5(1.4 \%)$ were MSc holder and above. This is in agreement with the study conducted by Satpute D et al, 2008; showed that diabetes particularly affects high prevalence rate in the people with lower educational levels in Bolivia and in Jamaica $(21,22)$. This is due to the fact that education is very important factors to control feeding style in order to minimize the development type II diabetes mellitus.

The distribution income as far as concerned, 106 (30.5\%) were grouped earned monthly income under high income categories and $25(7.2 \%)$ were grouped under low income categories. This is in agreement with the study conducted in Turkey 2000, which showed that higher percentage diabetes mellitus high under high income categories (23). The possible explanation is may be due to more consumption of non vegetable food who had earned monthly income greater than 1500 ETB.

Out of the total type II diabetic patients who visited the hospitals majority 277 (79.6\%) were urban resident and $71(20.4 \%)$ were rural resident. This is in line with the study conducted by Aboderin in 2001, which showed that high percentage of type II diabetes in urban area $(24,25)$. The possible reasons for high prevalence of type II diabetes in urban area is may be due to easily availability of non vegetable rich food and low working habit in urban.

Most of study participants $301(86.5 \%)$ were not had a family history of diabetes. This study is opposing the finding of Muhammad K et al., 2010 conducted in India, which showed that majority (69.4\%) of the respondents were having family history of type II diabetes mellitus (15). This difference is may be due to the fact that the respondents were not well informed about diabetic history of their family.

Out of the total type II diabetic patients $196(56.3 \%)$ were having BMI $>25 \mathrm{~kg} / \mathrm{m}^{2}, 17(4.9 \%)$ of type II patients were $<18.5 \mathrm{~kg} / \mathrm{m}^{2}$. This is in agreement with other study (26), which reported that type II diabetes is high in obese and overweight type study participants. This is due the fact that there are few insulin receptors, especially in liver, adipose tissue and skeletal muscle in obese than in lean subjects.

In present study, $57(16.3 \%)$ of the diabetic patients were doing physical activities, the rest $291(83.7 \%)$ participants were not involved in physical activities. This is supported with other studies $(27,28)$, which revealed that high percentage of diabetes among low physical activities participants. Other study done by Perry I et al, 1995, showed that Physical inactivity is a well-known risk factor for type II diabetes. The risk of diabetes is reduced by $50 \%$ among men who take moderately vigorous exercise (29). Lack of physical activity and unhealthy dietary habits are important modifiable risk factors for diabetes. The highest percentage of type II diabetes among lower level of physical activity is due to the fact that regular physical exercise reduces the risk of development of DM by regulating resistance in target tissue, by reducing body weight may also increases the number of receptors in target tissue.

In this study majority $282(81 \%)$ of participants were usually eat sugar and oil excess. This finding is supported by other studies who reports high prevalence of type II diabetes among non vegetarian (30). The possible justification of the high percentage of type II diabetes mellitus among eating sugar and oil excess is due to high accumulation of fats in the body. Carbohydrate and fat rich foods are increase insulin resistance by accumulation of fat which exposes the participants for development of type II diabetes mellitus.

Per distribution of drinking alcohol, 94 (27\%) of the study participants were heavy drunker and $4(1.1 \%)$ were mild drunker. There is study that supports this result (31). Possible explanation of high distribution of type II diabetes mellitus among type II diabetes mellitus is may be due to heavy consumption of alcohol damage beta cells in pancreas. 


\section{Conclusions and Recommendations}

A high proportion of risk factors observed in type II diabetes mellitus were being male, older age group greater than 50, overweight and with higher monthly income. The rate of type II diabetes mellitus was higher among urban residence. Most of the diabetic cases had BMI $>25 \mathrm{~kg} / \mathrm{m}^{2}$ which is a risk factor for the development of type II Diabetes. Dietary habits like eating excess oil and sugar were found to be risk factors for the development of type II diabetes mellitus. Level of education was found to be a very important factor for controlling diabetes mellitus. Chronic disease prevention and control programs, such as health education and promotion of regular physical exercise should be established so as to decrease the high prevalence of some of the modifiable risk factors like overweight and sedentary lifestyle observed in this study.

Conflict of interests: No conflict of interest.

\section{References}

1. Joslin's Diabetes Mellitus. Lea and Febiger: A Waverly company; 1994:133. 13th ed.

2. Harsh M. Text book of pathology. Jaypee brothers: New Delhi; 2005:650-3. 5th ed.

3. Centers for disease control and prevention (CDC). National Diabetes fact sheet: National estimates and general information on diabetes in the United States. Atlanta, GA: HHS; 1998.

4. Reaven G. The role of insulin resistance in human disease. Diabetes Care 1988; 37(12): 1595-1607.

5. Hamiel O, Dolan L, Daniels S, et al. Increased incidence of Non-insulin dependent diabetes mellitus among adolescents. Journal of Pediatrics 1996:128(1): 608-615.

6. Plagemann A, Harder T, Kohihoff R, et al. Glucose tolerance and insulin secretion in children of mothers with pregestional IDDM or gestational Diabetes. Diabetologia 1997; 40(9): 1094-1100.

7. Centers for Disease Control and Prevention. National diabetes fact sheet: general information and national estimates on diabetes in the United States, 2007.

8. American Diabetes Association. Report of the Expert Committee on the Diagnosis and Classification of Diabetes Mellitus. Diabetes Care 1997; 20:1183-1197

9. Centers for Disease Control and Prevention. Surveillance for diabetes mellitus-United States, 1980-1989, MWR 42 (SS-2):1-20, 1993

10. Araya G, Mistire W, Dawit Y, et al. Hypertension, obesity and central obesity in diabetics and non diabetics in Southern Ethiopia. Ethiop. J. Health Dev 2010; 24(2):145-147.

11. Stratton I, Adler A, Neil H, et al. Association of glycaemia with macrovascular and microvascular complications of Type II diabetes. BMJ 2000; 321; 405-412.

12. Khang Y, Lynch J, Kaplan G, et al. "Health inequalities in Republic of Korea: age- and sex-specific educational differences in the 10 leading causes of death. International Journal of Epidemiology 2004; 33(2): 299-308.

13. Gallagher D, et al. How useful is BMI for comparison of body fatness across age, sex and ethnic groups? American Journal of Epidemiology 1996; 143:228-239.

14. WHO. Surveillance of Noncommunicable Disease Risk Factors, the WHO Stepwise Approach. 2001 Geneva: 12-18, 51-79

15. Muhammad K, Prasanth N, Dilip C, et al. Assessment of risk factors among type 2 diabetic populations in South Malabar region of Kerala. Arch. Appl. Sci. Res. 2010; 2 (4):313-323.

16. Sekikawa A, Eguchi H, Tominaga M, et al. Prevalence of Type II diabetes mellitus and impaired glucose tolerance in a rural area of Japan. The Funagata Diabetes Study. J Diabetes Complications, 2000; 14:78-83.

17. Jaber L, Brown M, Hammad A, et al. Epidemiology, of diabetes among Arab Americans. Diabetes Care 2003; 26:308-313

18. King H, Djumaeva S, Abdullaev B, et al. Epidemiology of glucose intolerance and associated factors in Uzbekistan: a survey in Sirdaria province. Diabetes Res Clin Pract, 2002; 55:19-27.

19. Kelestimur F, Cetin M, Pasaoglu H et al. The prevalence of identification of risk factors for Type II diabetes mellitus and impaired glucose tolerance in Kayseri, Central Anatolia, Turkey. Acta Diabetol, 1999; 36:85-91.

20. Shobha D, Sahu A, Swapna M, et al. Indian.J.Comm.Med., 2007;34: 232 -236

21. Larsson H, Berglund G, Lindgarde F, et al. Comparison of ADA and WHO criteria f

22. Satpute D, Ingle P, Shimpi RD et al. Int. J. Pharma. Tech. 2008; Res, $1: 1-21$.

23. Yusuf Ö, Mualla A, Fahrettin, K.et al. Prevalence of Diabetes Mellitus and Affected Factors in the District of Kayseri Health Group Area. Turk J Med Sci .2000; 30:181-185

24. Aboderin I, Kalache A, Ben-Shlomo Y, et al. Life Course Perspectives on Coronary Heart Disease, Stroke and Diabetes: Key Issues and Implications for Policy and Research. Geneva: World Health Organization; 2001.

25. Shobhana R, Rama P, Lavanya A, et al. Cost Burden to Diabetic Patients with Foot Complications - A Study from Southern India. JAPI 2000; 48:1147-1150.

26. Williams G, Pickup J. Handbook of diabetes. 3rd ed. Blackwell Publishing; 2004

27. Flegal K. Prevalence of Diabetes and IGT in Mexican Americans, Cubans and Puerto-Ricans aged 20-74 years Second Hispanic Health and Nutrition Examination Survey (HANES II), 1982-84. Diabetes Care 1991; 14 (3): 
628-638.

28. WHO Technical Report Series. Prevention of Diabetes Mellitus. Report of a WHO Study Group, 1994 Geneva: 844: 5-18

29. Perry I, Wannamethee S, Walker M, et al. Factors for development of NIDDM in middle-aged British men. British Medical Journal 1995; 310: 560-564.

30. Alberto, Rajpthak, Swapnil . Public health 2001, 10.

31. Obembe A, Sijuwola A, Ayuba L, et al. Excessive alcohol consumption, risk of death and liver disease. A 5year hospital review at Jos, Medical Practitioner; 26 (5/6) 